\title{
A genome-wide association study identifies risk loci for spirometric measures among smokers of European and African ancestry
}

Sharon M. Lutz ${ }^{1 * \dagger}$, Michael H. Cho ${ }^{2 \dagger}$, Kendra Young ${ }^{3}$, Craig P. Hersh², Peter J. Castaldi ${ }^{2}$, Merry-Lynn McDonald ${ }^{2}$, Elizabeth Regann ${ }^{4}$, Manuel Mattheisen², Dawn L. DeMeo², Margaret Parker ${ }^{5}$, Marilyn Foreman ${ }^{6}$, Barry J. Make ${ }^{4}$, Robert L. Jensen ${ }^{7}$, Richard Casaburi ${ }^{8}$, David A. Lomas ${ }^{9}$, Surya P. Bhatt ${ }^{10}$, Per Bakke ${ }^{11}$, Amund Gulsvik ${ }^{11}$, James D. Crapo ${ }^{4}$, Terri H. Beaty ${ }^{5}$, Nan M. Laird ${ }^{12}$, Christoph Lange ${ }^{12}$, John E. Hokanson ${ }^{3 \dagger}$, Edwin K. Silverman ${ }^{2 \dagger}$ and ECLIPSE Investigators, and COPDGene Investigators

\begin{abstract}
Background: Pulmonary function decline is a major contributor to morbidity and mortality among smokers. Post bronchodilator $\mathrm{FEV}_{1}$ and $\mathrm{FEV}_{1} / \mathrm{FVC}$ ratio are considered the standard assessment of airflow obstruction. We performed a genome-wide association study (GWAS) in 9919 current and former smokers in the COPDGene study (6659 non-Hispanic Whites [NHW] and 3260 African Americans [AA]) to identify associations with spirometric measures (post-bronchodilator $\mathrm{FEV}_{1}$ and $\mathrm{FEV}_{1} / \mathrm{FVC}$ ). We also conducted meta-analysis of $\mathrm{FEV}_{1}$ and $\mathrm{FEV}_{1} / \mathrm{FVC}$ GWAS in the COPDGene, ECLIPSE, and GenKOLS cohorts (total $n=13,532$ ).
\end{abstract}

Results: Among NHW in the COPDGene cohort, both measures of pulmonary function were significantly associated with SNPs at the $15 q 25$ locus [containing CHRNA3/5, AGPHD1, IREB2, CHRNB4] (lowest $p$-value $=2.17 \times 10^{-11}$ ), and $\mathrm{FEV}_{1} / \mathrm{FVC}$ was associated with a genomic region on chromosome 4 [upstream of HHIP] (lowest $p$-value $=5.94 \times 10^{-10}$ ); both regions have been previously associated with COPD. For the meta-analysis, in addition to confirming associations to the regions near CHRNA3/5 and HHIP, genome-wide significant associations were identified for $\mathrm{FEV}_{1}$ on chromosome 1 [TGFB2] $\left(p\right.$-value $\left.=8.99 \times 10^{-9}\right), 9[\mathrm{DBH}]\left(p\right.$-value $\left.=9.69 \times 10^{-9}\right)$ and $19\left[\right.$ CYP2A6/7 $\left(p\right.$-value $\left.=3.49 \times 10^{-8}\right)$ and for $\mathrm{FEV}_{1} / \mathrm{FVC}$ on chromosome 1 [TGFB2] $\left(p\right.$-value $\left.=8.99 \times 10^{-9}\right), 4$ [FAM13A] $\left(p\right.$-value $\left.=3.88 \times 10^{-12}\right), 11[$ MMP3/12] $\left(p\right.$-value $\left.=3.29 \times 10^{-10}\right)$ and $14\left[\right.$ RIN3] $\left(p\right.$-value $\left.=5.64 \times 10^{-9}\right)$.

Conclusions: In a large genome-wide association study of lung function in smokers, we found genome-wide significant associations at several previously described loci with lung function or COPD. We additionally identified a novel genome-wide significant locus with $\mathrm{FEV}_{1}$ on chromosome $9[\mathrm{DBH}]$ in a meta-analysis of three study populations.

Keywords: Chronic obstructive pulmonary disease, DBH, FEV 1 , FEV 1 /FVC, Genome-wide association study, Spirometry

\section{Background}

In the United States, chronic obstructive pulmonary disease (COPD) is the third leading cause of death [1]. The major environmental risk factor for COPD is cigarette smoking, but only a minority of smokers will develop COPD during their lifetime [2, 3]. COPD risk is most

\footnotetext{
*Correspondence: sharon.lutz@ucdenver.edu

${ }^{\dagger}$ Equal contributors

'Department of Biostatistics, University of Colorado Anschutz Medical Campus, 13001 E. 17th Place, B119 Bldg. 500, W3128, Aurora, CO 80045, USA Full list of author information is available at the end of the article
}

likely the cumulative result of genetic factors, environmental factors such as cigarette smoking, developmental factors, and gene-by-environment interactions [4].

A diagnosis of COPD is based on post bronchodilator spirometric measures of the forced expiratory volume in the first second $\left(\mathrm{FEV}_{1}\right)$ and the forced vital capacity (FVC), the total volume of air expired after a maximal inhalation [5]. The ratio of $\mathrm{FEV}_{1} / \mathrm{FVC}$ is a widely used measure of airflow obstruction [3]. Understanding the genetics underlying these spirometric

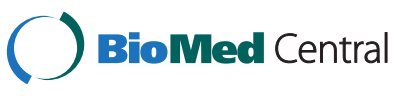

(C) 2015 Lutz et al. Open Access This article is distributed under the terms of the Creative Commons Attribution 4.0 International License (http://creativecommons.org/licenses/by/4.0/), which permits unrestricted use, distribution, and reproduction in any medium, provided you give appropriate credit to the original author(s) and the source, provide a link to the Creative Commons license, and indicate if changes were made. The Creative Commons Public Domain Dedication waiver (http://creativecommons.org/publicdomain/zero/1.0/) applies to the data made available in this article, unless otherwise stated. 
measurements may help increase our knowledge of the genetics of COPD.

Initial genome wide analyses of spirometric measures of pulmonary function using family-based linkage analyses identified broad genomic regions on chromosome $1,2,4,8$, and 18 [6]. Subsequent genome wide association studies in the Framingham cohort, a population based sample, identified the HHIP gene as a susceptibility locus for $\mathrm{FEV}_{1} / \mathrm{FVC}$ [7]. This Framingham cohort was combined with several other population based cohorts forming the CHARGE consortium of greater than 20,000 individuals. This sample, along with the SpiroMeta consortium, another population based sample of over 20,000 individuals, provided the sample for a series of meta-analyses; one used CHARGE as a discovery population with subsequent replication in SpiroMeta [8], a second used SpiroMeta as the discovery population with selected genotyping in an additional 32,000 individuals and a pooled meta analysis with the CHARGE consortium [9], and a third combined CHARGE and SpiroMeta in the discovery phase $(n=48,201)$ with SNP replication in an additional combined population based sample of 46,411 individuals [10]. The first two of these meta-analyses confirmed HHIP as a susceptibility locus for $\mathrm{FEV}_{1} / \mathrm{FVC}$ and identified multiple additional loci that were significantly associated with spriometric measures of pulmonary function. The third meta-analysis identified 16 new loci for pre bronchodilator pulmonary function in addition to 10 previously reported loci [10].

To examine the role of smoking on the genetic susceptibility to spirometric measures of pulmonary function, the CHARGE/SpiroMeta samples with additional European ancestry samples totalling more than 30,000 individuals were stratified by smoking status (ever versus never smokers) [11]. Among smokers, a novel signal on chromosome 15q25 (CHRNA5/A3/B4 was identified for airflow obstruction defined as pre bronchodialator $\mathrm{FEV}_{1}$ and $\mathrm{FEV}_{1} / \mathrm{FVC}$ below the lower limit of normal. This is the major genomic region for nicotine dependence and smoking exposure and related traits [12]. More recently a genome wide study of pulmonary function identified the CYP2U1 gene [involved in nicotine metabolism], however, this was not replicated in the CHARGE/SpiroMeta sample [13].

Given that smoking is the major environmental determinant of pulmonary function decline, we performed a GWAS of the full quantitative range of post bronchodilator pulmonary function in 9919 current and former smokers of the COPDGene study with complete data and genome wide genotyping. We hypothesized that we would identify novel genetic loci and replicate known genomic regions affecting pulmonary function by performing a GWAS of post bronchodilator spirometric measures in the COPDGene study, a multi-center observational study designed to identify genetic factors associated with risk of COPD. In addition, to insure the GWAS results are generalizable beyond a single study, we performed a meta-analysis of post bronchodilator $\mathrm{FEV}_{1}$ and $\mathrm{FEV}_{1} / \mathrm{FVC}$ ratio over three similar studies: the COPDGene, ECLIPSE, and GenKOLS studies. Characteristics of the 3 studies (COPDGene, ECLIPSE, and GenKOLS) are given in Table 1. We also assessed whether different genomic regions were associated with spirometric measures of pulmonary function separately among non-Hispanic white (NHW) and AfricanAmerican (AA) COPDGene subjects.

\section{Results}

\section{COPDGene GWAS in Non-Hispanic Whites}

For $\mathrm{FEV}_{1}$ among all NHW COPDGene participants, several SNPs at the 15q25 locus [near CHRNA3, CHRNA5, CHRNB4, AGPHD1, and IREB2] reached genome-wide significance. For $\mathrm{FEV}_{1} / \mathrm{FVC}$ among all NHW COPDGene subjects, several SNPs in the same region on chromosome 15 reached genome-wide significance. Tables 2 and 3 show $p$-values for the most significant SNPs in these regions. Additional file 1: Tables S5-S6 list all SNPs with a $p$-value less than $5 \times 10^{-6}$.

\section{COPDGene GWAS in African Americans}

For both $\mathrm{FEV}_{1}$ and $\mathrm{FEV}_{1} / \mathrm{FVC}$ among all AA COPDGene subjects, there were a few SNPs that were genome-wide significant, but these SNPs were all imputed, with low minor allele frequency $(<5 \%)$, and in a region with no other non-imputed SNPs. Therefore, we are not confident that these signals are valid associations. The top SNPs for these analyses with $p$-values less than $5 \times 10^{-6}$ can be found in the Additional file 1: Tables S1 and S2.

\section{Results from the Meta-Analysis: COPDGene participants combined with the ECLIPSE and GenKOLS cohorts}

For $\mathrm{FEV}_{1}$ and $\mathrm{FEV}_{1} / \mathrm{FVC}$, most of the genome-wide significant results were again at the $15 \mathrm{q} 25$ locus, on chromosome 4 in FAM13A, and on chromosome 4 near HHIP. In addition, Table 2 shows other genome-wide significant findings for $\mathrm{FEV}_{1} / \mathrm{FVC}$ on chromosome 1 [TGFB2], $9[D B H]$ and 19 [CYP2A6, CYP2A7]. Table 3 shows other genome-wide significant findings for $\mathrm{FEV}_{1}$ on chromosome 1 [TGFB2], 11 [MMP3,MMP12] and 14 [RIN3]. The top SNPs for these analyses with $p$-values less than $5 \times 10^{-6}$ can be found in the Additional file 1 : Tables S9 and S10.

\section{Case-only analyses among NHW in COPDGene, AA in COPDGene, and within the meta-analysis}

In addition, we examined the genetic susceptibility to variation in these pulmonary function phenotypes in COPD cases only (GOLD stages 2-4) (2820 NHW in 
Table 1 Characteristics of COPDGene, ECLIPSE, and GenKOLS Subjects included in genome-wide association analysis. For continuous variables, the mean is given first followed by the standard deviation

\begin{tabular}{|c|c|c|c|c|}
\hline & COPDGene NHW & COPDGene AA & ECLIPSE & GenKOLS \\
\hline Sample size (\#COPD cases) & 6659 (2812) & $3260(821)$ & $1942(1764)$ & $1671(863)$ \\
\hline Gender (\% male) & $47.73 \%$ & $44.79 \%$ & $66.17 \%$ & $58.71 \%$ \\
\hline Age (years) & $62.0(8.9)$ & $54.6(7.2)$ & $63.1(7.6)$ & $60.7(11.1)$ \\
\hline Height (cm) & $169.7(9.5)$ & $171.0(9.7)$ & $169.7(9.1)$ & $170.8(8.9)$ \\
\hline BMI (kg/m2) & $28.7(6.0)$ & $29.07(6.7)$ & $26.8(5.5)$ & $25.9(4.6)$ \\
\hline Pack-years & $47.2(26.0)$ & $38.3(21.6)$ & $48.6(27.7)$ & $26.0(17.4)$ \\
\hline Current Smoking (\%) & $38.9 \%$ & $80.0 \%$ & $34.8 \%$ & $43.8 \%$ \\
\hline FEV1 (L) & $2.20(0.95)$ & $2.30(0.86)$ & $1.50(0.78)$ & $2.38(1.10)$ \\
\hline FEV1 (\% predicted) & $74.0(26.0)$ & $82.0(23.9)$ & $53.1(23.2)$ & $72.2(26.2)$ \\
\hline FEV1/FVC & $0.64(0.17)$ & $0.72(0.14)$ & $0.48(0.15)$ & $0.65(0.17)$ \\
\hline
\end{tabular}

Notes: $\mathrm{FEV}_{1}, \mathrm{FEV}_{1}\left(\%\right.$ predicted), and $\mathrm{FEV}_{1} / \mathrm{FVC}$ are all based on post-bronchodilator spirometry

COPDGene, 821 AA in COPDGene, 1764 NHW in ECLIPSE, and 863 NHW in GenKOLS). While no SNPs reached genome-wide significance for either $\mathrm{FEV}_{1} / \mathrm{FVC}$ or $\mathrm{FEV}_{1}$ in the case-only analyses, Additional file 1 : Tables S3-S4, S7-S8, and S11-S12 show the top SNPs for these analyses. Some of the regions that met genome-wide significance in the entire study population had at least nominal evidence for association in COPD cases only. In addition to the well-established COPD genetic loci near HHIP, FAM13A, and CHRNA3/5, the $M M P 3 / M M P 12$ and $D B H$ regions had $P<0.001$ evidence for association to lung function levels within COPD cases. Power may have been limited in the caseonly analysis, but it is also possible that genetic determinants are more important for the presence/absence of COPD than for the severity of airflow obstruction within COPD cases.

\section{Comparison of Findings among AA and NHW}

Figure 1 shows how the $p$-values of the SNPs on chromosome 15 [CHRNA3, CHRNA5, CHRNB4, AGPHD1, and IREB2] compare among the NHW and AA COPDGene

Table 2 Genome-wide significant results for $\mathrm{FEV}_{1} / \mathrm{FVC}$ in the meta-analysis. The SNP with the lowest $p$ value within each region or gene is listed ordered by chromosome number

\begin{tabular}{|c|c|c|c|c|c|c|c|c|c|c|c|c|c|}
\hline \multirow[t]{2}{*}{ SNP } & \multirow[t]{2}{*}{$\begin{array}{l}\text { Position } \\
\text { (bp) }\end{array}$} & \multirow[t]{2}{*}{$\mathrm{CHR}$} & \multirow[t]{2}{*}{ Nearest Gene } & \multirow[t]{2}{*}{$\begin{array}{l}\text { Coded } \\
\text { Allele }\end{array}$} & \multicolumn{3}{|c|}{ COPDGene NHW } & \multicolumn{3}{|c|}{ COPDGene AA } & \multicolumn{3}{|c|}{$\begin{array}{l}\text { Meta-Analysis of COPDGene } \\
\text { NHW, COPDGene AA, ECLIPSE } \\
\text { and GenKOLS }\end{array}$} \\
\hline & & & & & $\begin{array}{l}\text { Allele } \\
\text { Freq }\end{array}$ & Beta & $P$ & $\begin{array}{l}\text { Allele } \\
\text { Freq }\end{array}$ & Beta & $P$ & $\begin{array}{l}\text { Allele } \\
\text { Freq }\end{array}$ & Beta & $P$ \\
\hline rs72738834 & 218623888 & 1 & TGFB2 & $\mathrm{G} / \mathrm{G} / \mathrm{A}$ & 0.79 & -0.01 & 0.00276 & 0.834 & -0.017 & 5.34E-05 & 0.81 & -0.013 & $6.51 \mathrm{E}-09$ \\
\hline rs6837671 & 89873092 & 4 & FAM13A & $\mathrm{G} / \mathrm{G} / \mathrm{A}$ & 0.60 & -0.01 & $5.18 \mathrm{E}-06$ & 0.416 & 0.007 & 0.03196 & 0.535 & 0.013 & $5.45 \mathrm{E}-13$ \\
\hline rs13141641 & 145506456 & 4 & LOC646576 (near HHIP) & $\mathrm{C} / \mathrm{C} / \mathrm{T}$ & 0.60 & -0.02 & 5.72E-09 & 0.888 & -0.015 & 0.00477 & 0.632 & -0.018 & $9.52 \mathrm{E}-20$ \\
\hline rs72981684 & 102724211 & 11 & MMP12 & $\mathrm{T} / \mathrm{T} / \mathrm{T}$ & 0.88 & -0.02 & $2.46 \mathrm{E}-07$ & 0.968 & -0.024 & 0.02783 & 0.114 & 0.019 & $3.92 \mathrm{E}-10$ \\
\hline rs72981675 & 102721251 & 11 & MMP3 & $\mathrm{T} / \mathrm{T} / \mathrm{T}$ & 0.88 & -0.02 & $2.80 \mathrm{E}-07$ & 0.968 & -0.024 & 0.02842 & 0.114 & 0.019 & $3.65 E-10$ \\
\hline rs754388 & 93115410 & 14 & RIN3 & $\mathrm{G} / \mathrm{G} / \mathrm{C}$ & 0.82 & -0.02 & 3.17E-07 & 0.85 & -0.01 & 0.00898 & 0.83 & -0.014 & $5.54 \mathrm{E}-09$ \\
\hline rs56077333 & 78899003 & 15 & CHRNA3 & $\mathrm{A} / \mathrm{A} / \mathrm{A}$ & 0.65 & -0.02 & 4.70E-10 & 0.816 & 0.019 & $6.02 \mathrm{E}-06$ & 0.314 & -0.018 & 9.55E-20 \\
\hline rs8042849 & 78817929 & 15 & AGPHD1 & $\mathrm{C} / \mathrm{C} / \mathrm{T}$ & 0.56 & 0.02 & $2.71 \mathrm{E}-10$ & 0.568 & 0.008 & 0.02729 & 0.561 & 0.015 & 2.81E-15 \\
\hline rs17486278 & 78867482 & 15 & CHRNA5 & $C / C / A$ & 0.63 & 0.02 & 2.28E-09 & 0.709 & 0.016 & $3.14 \mathrm{E}-06$ & 0.65 & 0.017 & 4.48E-20 \\
\hline rs58365910 & 78849034 & 15 & PSMA4 & $\mathrm{C} / \mathrm{C} / \mathrm{T}$ & 0.628 & 0.016 & $2.28 \mathrm{E}-09$ & 0.747 & 0.011 & 0.00475 & 0.655 & 0.015 & $1.24 \mathrm{E}-15$ \\
\hline rs17487223 & 78923987 & 15 & CHRNB4 & $\mathrm{G} / \mathrm{T} / \mathrm{T}$ & 0.616 & 0.016 & 9.73E-09 & 0.882 & 0.013 & 0.00999 & 0.349 & -0.016 & $3.28 \mathrm{E}-15$ \\
\hline rs17484524 & 78772676 & 15 & IREB2 & $\mathrm{G} / \mathrm{G} / \mathrm{A}$ & 0.639 & 0.015 & 1.86E-07 & 0.936 & 0.01 & 0.138 & 0.666 & 0.015 & 4.83E-13 \\
\hline rs12913260 & 79071095 & 15 & ADAMTS7 & A/A/A & 0.59 & 0.02 & 1.60E-05 & 0.88 & 0.004 & 0.53 & 0.371 & -0.015 & 4.82E-08 \\
\hline rs56113850 & 41353107 & 19 & CYP2A6 & $\mathrm{T} / \mathrm{C} / \mathrm{T}$ & 0.60 & -0.02 & 2.46E-05 & 0.562 & 0.01 & 0.01955 & 0.462 & 0.014 & 5.19E-09 \\
\hline
\end{tabular}

The "Coded Allele" column refers to the reference allele where the first reference allele is for the COPDGene NHW cohort, the second reference allele is for the COPDGene AA cohort, and the third reference allele is for the meta-analysis of COPDGene NHW, COPDGene AA, ECLIPSE and GenKOLS. Note that FEV $/$ FVC was measured on the proportion scale (0-1) and not the percentage scale (0-100) 
Table 3 Genome-wide significant results for $\mathrm{FEV}_{1}$ in the meta-analysis. The SNP with the lowest $p$ value within each region or gene is listed ordered by chromosome number

\begin{tabular}{|c|c|c|c|c|c|c|c|c|c|c|c|c|c|}
\hline \multirow[t]{2}{*}{ SNP } & \multirow[t]{2}{*}{$\begin{array}{l}\text { Position } \\
\text { (bp) }\end{array}$} & \multirow[t]{2}{*}{$\mathrm{CHR}$} & \multirow[t]{2}{*}{ Gene/Nearest Gene } & \multirow[t]{2}{*}{$\begin{array}{l}\text { Coded } \\
\text { Allele }\end{array}$} & \multicolumn{3}{|c|}{ COPDGene NHW } & \multicolumn{3}{|c|}{ COPDGene AA } & \multicolumn{3}{|c|}{$\begin{array}{l}\text { Meta-Analysis of COPDGene } \\
\text { NHW, COPDGene AA, ECLIPSE } \\
\text { and GenKOLS }\end{array}$} \\
\hline & & & & & $\begin{array}{l}\text { Allele } \\
\text { Freq }\end{array}$ & Beta & $P$ & $\begin{array}{l}\text { Allele } \\
\text { Freq }\end{array}$ & Beta & $P$ & $\begin{array}{l}\text { Allele } \\
\text { Freq }\end{array}$ & Beta & $P$ \\
\hline rs10863398 & 218588279 & 1 & TGFB2 & $\mathrm{A} / \mathrm{A} / \mathrm{A}$ & 0.883 & -0.055 & 0.00539 & 0.695 & -0.07 & 4.94E-05 & 0.202 & 0.067 & $1.06 \mathrm{E}-08$ \\
\hline rs138641402 & 145445779 & 4 & LOC646576 (near HHIP) & $\mathrm{T} / \mathrm{T} / \mathrm{A}$ & 0.641 & -0.067 & $2.28 \mathrm{E}-06$ & 0.919 & -0.09 & 0.00479 & 0.668 & -0.083 & 8.99E-15 \\
\hline rs6837671 & 89873092 & 4 & FAM13A & $\mathrm{G} / \mathrm{G} / \mathrm{A}$ & 0.595 & 0.057 & $1.11 \mathrm{E}-05$ & 0.416 & 0.059 & 0.00024 & 0.537 & 0.064 & $2.89 \mathrm{E}-13$ \\
\hline rs1108581 & 136505241 & 9 & $D B H$ & A/A/A & 0.196 & 0.068 & $2.29 \mathrm{E}-05$ & 0.438 & 0.045 & 0.00394 & 0.292 & -0.058 & $8.72 \mathrm{E}-09$ \\
\hline rs56077333 & 78899003 & 15 & CHRNA3 & $\mathrm{A} / \mathrm{A} / \mathrm{A}$ & 0.649 & 0.089 & 9.49E-11 & 0.816 & 0.079 & 0.00014 & 0.318 & -0.084 & 5.29E-18 \\
\hline rs8031948 & 78816057 & 15 & AGPHD1 & $\mathrm{T} / \mathrm{T} / \mathrm{T}$ & 0.63 & 0.084 & $2.61 \mathrm{E}-10$ & 0.838 & 0.05 & 0.02287 & 0.336 & -0.075 & $2.86 \mathrm{E}-15$ \\
\hline rs17486278 & 78867482 & 15 & CHRNA5 & $\mathrm{C} / \mathrm{C} / \mathrm{A}$ & 0.632 & 0.085 & 1.44E-10 & 0.709 & 0.073 & 4.31E-05 & 0.647 & 0.079 & $3.48 \mathrm{E}-18$ \\
\hline rs17487223 & 78923987 & 15 & CHRNB4 & $\mathrm{T} / \mathrm{T} / \mathrm{T}$ & 0.616 & 0.081 & 1.82E-09 & 0.882 & 0.066 & 0.01205 & 0.353 & -0.076 & $2.06 \mathrm{E}-14$ \\
\hline rs2568494 & 78740964 & 15 & IREB2 & $\mathrm{G} / \mathrm{G} / \mathrm{A}$ & 0.367 & -0.076 & $7.25 \mathrm{E}-09$ & 0.443 & -0.028 & 0.07723 & 0.545 & -0.062 & $1.66 \mathrm{E}-12$ \\
\hline rs58365910 & 78849034 & 15 & PSMA4 & $\mathrm{C} / \mathrm{C} / \mathrm{T}$ & 0.628 & 0.085 & $1.65 \mathrm{E}-10$ & 0.747 & 0.045 & 0.01584 & 0.652 & 0.072 & 6.69E-15 \\
\hline rs56113850 & 41353107 & 19 & CYP2A6 & $\mathrm{T} / \mathrm{C} / \mathrm{T}$ & 0.596 & -0.067 & 0.00045 & 0.562 & 0.048 & 0.01985 & 0.458 & 0.067 & $1.51 \mathrm{E}-08$ \\
\hline
\end{tabular}

The "Coded Allele" column refers to the reference allele where the first reference allele is for the COPDGene NHW cohort, the second reference allele is for the COPDGene AA cohort, and the third reference allele is for the meta-analysis of COPDGene NHW, COPDGene AA, ECLIPSE and GenKOLS

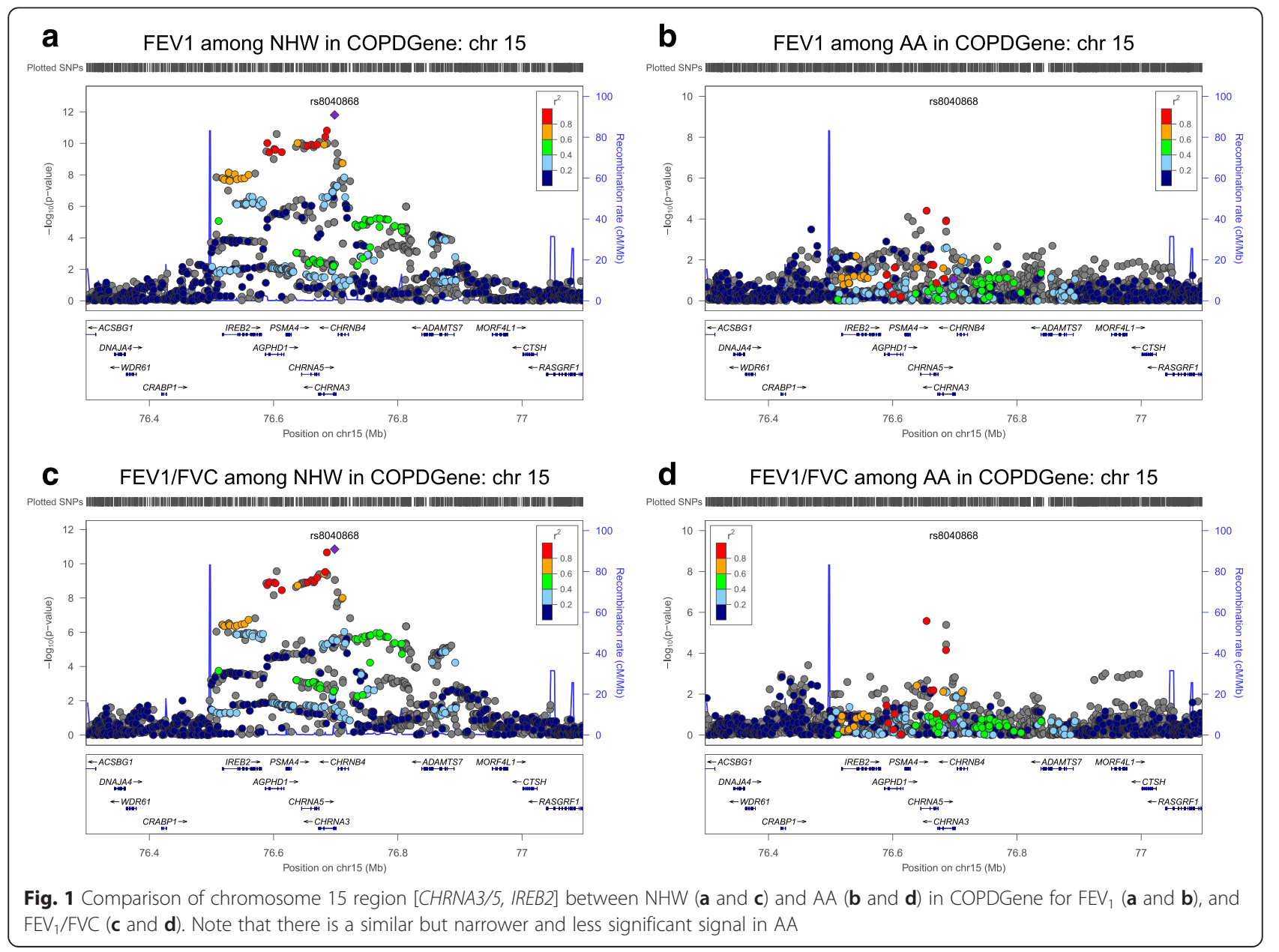


subjects for both spirometric measures of pulmonary function. While no single SNP reaches genome-wide significance in this region among the AA subjects, there is a region near CHRNA3 with several SNPs that have $p$-values in the range of $5 \times 10^{-6}$. It appears that the results among AA are similar to those in NHW but may not have the power to reach genomewide significance due to the smaller sample size. Figure 2 shows qualitatively different association results in the NHW (highly associated) and AA (not associated) subjects for the region on chromosome 4 near HHIP, although reduced power in the AA subjects could contribute to reduced evidence for association.

Comparison to previously published spirometry GWA studies We considered genome-wide significant results from a previously published spirometry GWA analysis in general population samples, which combined the Cohorts for Heart and Aging Research in Genomic Epidemiology (CHARGE) and SpiroMeta studies [10]. Table 4 shows $p$-values of these loci from the CHARGE/SpiroMeta analyses in the COPDGene subpopulations analysed above. Except for HHIP and $F A M 13 A$, none of the other regions achieved genome-wide significance $\left(p\right.$-value $\left.<5 \times 10^{-8}\right)$ in the COPDGene cohort or in the meta-analysis of COPDGene, GenKOLS, and ECLIPSE. However, quite a few SNPs had a signal in the same direction as CHARGE/SpiroMeta and met a nominal levels of significance using Bonferroni correction ( $p$-value $<0.0018$ for the 28 regions tested) in the meta-analysis of these three study populations, including SNPs in or near AGER, MFAP2, RARB, GSTCD, NPNT, SPATA9, ADAM19, THSD4, and CFDP1.

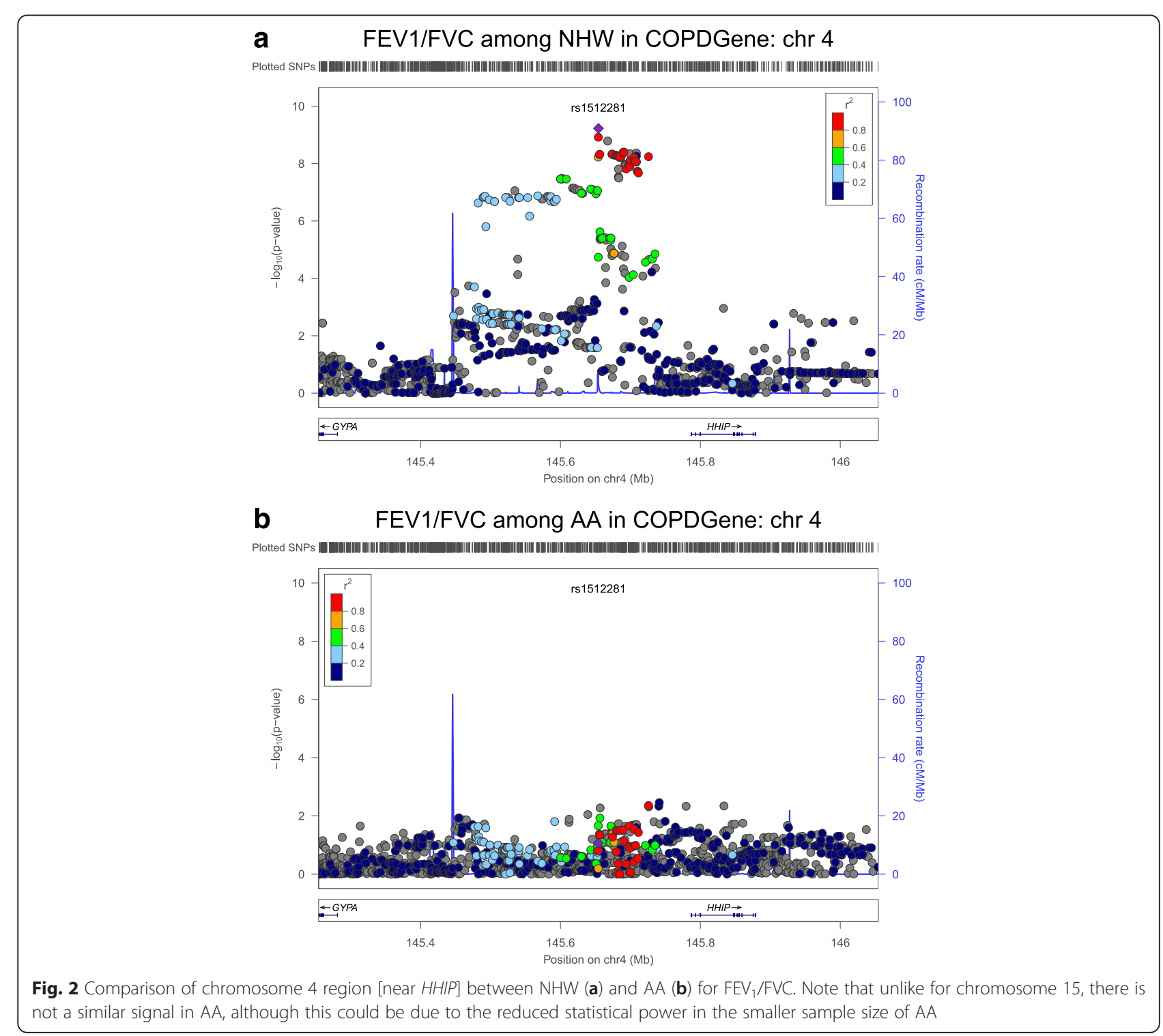


Table 4 Comparison of the current GWA results with the novel genome wide results from the largest GWAS of pre bronchodilator $\mathrm{FEV}_{1}$ and $\mathrm{FEV}_{1} / \mathrm{FVC}$ ratio in the CHARGE/SpiroMeta consortium

\begin{tabular}{|c|c|c|c|c|c|c|c|}
\hline \multirow[t]{2}{*}{ chr } & \multirow[t]{2}{*}{ Gene } & \multirow[t]{2}{*}{$\begin{array}{l}\text { SNP/Position } \\
\text { (bp) }\end{array}$} & \multirow[t]{2}{*}{ Phenotype } & \multirow{2}{*}{$\begin{array}{l}\text { CHARGE/SpiroMeta } \\
\text { Coded Allele/Beta/P-value }\end{array}$} & COPDGene NHW & COPDGene AA & \multirow[t]{2}{*}{$\begin{array}{l}\text { Meta-analysis: COPDGene, } \\
\text { ECLIPSE, and GenKOLS }\end{array}$} \\
\hline & & & & & \multicolumn{2}{|c|}{ Coded Allele/Allele Frequency/Beta/P-value } & \\
\hline \multirow[t]{2}{*}{1} & MFAP2 & rs2284746 & $\mathrm{FEV}_{1} / \mathrm{FVC}$ & $\mathrm{G} /-0.04 / 7.50 \mathrm{e}-16$ & G/0.476/0.007/0.012 & $\mathrm{G} / 0.807 / 0.005 / 0.256$ & C/0.545/0.007/1.4E-04 \\
\hline & & 17306675 & & & & & \\
\hline \multirow[t]{2}{*}{1} & TGFB2 & rs993925* & $\mathrm{FEV}_{1} / \mathrm{FVC}$ & T/0.034/1.16e-08 & C/0.33/0.002/0.551 & C/0.32/0.004/0.232 & $\mathrm{T} / 0.594 / 0.002 / 0.3655$ \\
\hline & & 218860068 & & & & & \\
\hline \multirow[t]{2}{*}{2} & TNS1 & rs2571445 & $\mathrm{FEV}_{1}$ & G/0.047/9.83e-11 & G/0.393/-0.027/0.03526 & G/0/201/0.007/0.7201 & $A / 0.645 /-0.015 / 0.0996$ \\
\hline & & 218683154 & & & & & \\
\hline \multirow[t]{2}{*}{2} & HDAC4 & rs12477314 & $\mathrm{FEV}_{1} / \mathrm{FVC}$ & T/0.041/1.68e-08 & T/0.8/-0.001/0.8196 & $\mathrm{T} / 0.963 /-0.003 / 0.683$ & $\mathrm{~T} / 0.187 / 0.003 / 0.1802$ \\
\hline & & 239877148 & & & & & \\
\hline \multirow[t]{2}{*}{3} & $R A R B$ & rs1529672 & $\mathrm{FEV}_{1} / \mathrm{FVC}$ & C/-0.048/3.97e-14 & C/0.162/0.015/1.88E-05 & C/0.20/0.005/0.2018 & $\mathrm{A} / 0.82 / 0.01 / 6.72 \mathrm{E}-06$ \\
\hline & & 25520582 & & & & & \\
\hline \multirow[t]{2}{*}{3} & MECOM & rs1344555 & $\mathrm{FEV}_{1}$ & T/-0.034/2.65e-08 & $\mathrm{T} / 0.809 / 0.017 / 0.293$ & T/0.799/-0.037/0.07322 & T/0.194/-0.008/0.4903 \\
\hline & & 169300219 & & & & & \\
\hline \multirow[t]{2}{*}{4} & FAM13A & rs2045517 & $\mathrm{FEV}_{1} / \mathrm{FVC}$ & T/-0.047/2.0e-11 & T/0.595/0.012/5.32E-06 & $\mathrm{T} / 0.343 / 0.005 / 0.1522$ & T/0.485/-0.012/5.66E-12 \\
\hline & & 89870964 & & & & & \\
\hline \multirow[t]{2}{*}{4} & GSTCD & rs10516526 & $\mathrm{FEV}_{1}$ & G/0.108/4.75e-14 & G/0.935/-0.117/6.16E-06 & G/0.951/0.002/0.9647 & A/0.694/-0.066/0.00029 \\
\hline & & 106688904 & & & & & \\
\hline \multirow[t]{2}{*}{4} & NPNT & rs17331332 & $\mathrm{FEV}_{1}$ & $G /-0.102 / 1.11 e-12$ & A/0.933/-0.128/6.16E-06 & A/0.979/-0.14/0.03813 & A/0.064/0.093/3.19E-06 \\
\hline & & 106808107 & & & & & \\
\hline \multirow[t]{2}{*}{4} & HHIP & rs1032296 & $\mathrm{FEV}_{1} / \mathrm{FVC}$ & $T /-0.05 / 3.42 \mathrm{e}-12$ & C/0.413/-0.011/1.82E-05 & C/0.17/-0.01/0.023 & T/0.59/-0.011/1.80E-08 \\
\hline & & 145434688 & $\mathrm{FEV}_{1}$ & T/-0.047/8.74e-11 & $\mathrm{A} / 0.414 /-0.045 / 0.0004$ & $\mathrm{~A} / 0.17 /-0.061 / 0.004$ & T/0.585/-0.048/2.27E-07 \\
\hline \multirow[t]{2}{*}{5} & SPATA9 & rs153916 & $\mathrm{FEV}_{1} / \mathrm{FVC}$ & T/-0.031/2.12e-08 & C/0.539/-0.008/0.002 & $C / 0.57 /-0.008 / 0.017$ & T/0.55/-0.008/3.06E-05 \\
\hline & & 95036700 & & & & & \\
\hline \multirow[t]{2}{*}{5} & HTR4 & rs11168048 & $\mathrm{FEV}_{1} / \mathrm{FVC}$ & T/-0.047/5.97e-11 & $\mathrm{T} / 0.42 / 0.01 / 0.0102$ & $\mathrm{~T} / 0.23 /-0.002 / 0.5213$ & $\mathrm{~T} / 0.425 /-0.004 / 0.04823$ \\
\hline & & 145479139 & $\mathrm{FEV}_{1}$ & T/-0.046/2.43e-10 & T/0.42/0.03/0.008 & $\mathrm{T} / 0.23 / 0.01 / 0.548$ & T/0.428/-0.02/0.01452 \\
\hline \multirow[t]{2}{*}{5} & ADAM19 & rs11134779 & $\mathrm{FEV}_{1} / \mathrm{FVC}$ & G/-0.042/6.01e-09 & G/0.65/0.005/0.086 & $\mathrm{G} / 0.411 / 0.007 / 0.024$ & A/0.574/0.006/8.00E-04 \\
\hline & & 156936766 & & & & & \\
\hline \multirow[t]{2}{*}{6} & AGER & rs2070600 & $\mathrm{FEV}_{1} / \mathrm{FVC}$ & T/0.126/9.07e-15 & $\mathrm{A} / 0.043 / 0.035 / 6.22 \mathrm{E}-08$ & $\mathrm{~A} / 0.01 /-0.003 / 0.849$ & $\mathrm{~T} / 0.31 / 0.026 / 2.24 \mathrm{e}-07$ \\
\hline & & 32151443 & $\mathrm{FEV}_{1}$ & T/0.025/1.271e-12 & C/0.043/0.121/0.0001 & A/0.01/0.054/0.522 & T/0.302/0.081/7.43e-04 \\
\hline \multirow[t]{2}{*}{6} & GPR126 & rs3817928 & $\mathrm{FEV}_{1} / \mathrm{FVC}$ & G/0.059/2.27e-12 & G/0.806/-0.003/0.311 & G/0.802/-0.015/3e-04 & A/0.807/-0.006/0.01394 \\
\hline & & 142750516 & & & & & \\
\hline \multirow[t]{2}{*}{6} & LOC153910 & rs262129 & $\mathrm{FEV}_{1} / \mathrm{FVC}$ & G/0.056/2.91e-13 & G/0.704/-0.006/0.043 & G/0.19/-0.004/0.3078 & A/0.59/-0.005/0.009 \\
\hline & & 142853144 & & & & & \\
\hline \multirow[t]{2}{*}{6} & ZKSCAN3 & rs6903823 & $\mathrm{FEV}_{1}$ & $\mathrm{G} /-0.037 / 2.18 \mathrm{e}-10$ & G/0.777/0.013/0.380 & G/0.592/-0.049/0.00233 & $\mathrm{A} / 0.712 /-0.013 / 0.193$ \\
\hline & & 28322296 & & & & & \\
\hline 6 & NCR3 & rs2857595 & $\mathrm{FEV}_{1} / \mathrm{FVC}$ & $\mathrm{G} / 0.037 / 2.28 \mathrm{e}-10$ & G/0.188/0/0.9309 & G/0.423/-0.001/0.7777 & $\mathrm{A} / 0 /-0.001 / 0.6174$ \\
\hline & & 31568469 & & & & & \\
\hline 6 & ARMC2 & rs2798641 & $\mathrm{FEV}_{1} / \mathrm{FVC}$ & T/-0.041/8.35e-09 & C/0.191/-0.009/0.005 & C/0.053/-0.005/0.505 & $\mathrm{T} / 0.825 /-0.008$ \\
\hline & & 109268050 & & & & & 0.002 \\
\hline 9 & PTCH1 & rs16909859 & $\mathrm{FEV}_{1} / \mathrm{FVC}$ & $\mathrm{G} / 0.08 / 7.45 \mathrm{e}-10$ & $\mathrm{G} / 0.075 /-0.004 / 0.432$ & G/0.295/-0.005/0.156 & $\mathrm{A} / 0.67 /-0.004 / 0.1468$ \\
\hline & & 98204792 & & & & & \\
\hline 10 & CDC123 & rs7068966 & $\mathrm{FEV}_{1} / \mathrm{FVC}$ & T/0.033/6.13e-13 & C0.522/0.002/0.516 & T/0.782/-0.008/0.04255 & $\mathrm{T} / 0.449 / 0.003 / 0.07659$ \\
\hline
\end{tabular}


Table 4 Comparison of the current GWA results with the novel genome wide results from the largest GWAS of pre bronchodilator $\mathrm{FEV}_{1}$ and $\mathrm{FEV}_{1} / \mathrm{FVC}$ ratio in the CHARGE/SpiroMeta consortium (Continued)

\begin{tabular}{|c|c|c|c|c|c|c|c|}
\hline \multirow[t]{2}{*}{10} & C10orf1 & rs11001819 & $\mathrm{FEV}_{1}$ & G/-0.029/2.98e-12 & $\mathrm{A} / 0.524 /-0.009 / 0.493$ & A/0.661/0.012/0.4849 & $\mathrm{A} / 0.45 / 0.006 / 0.472$ \\
\hline & & 78315224 & & & & & \\
\hline \multirow[t]{2}{*}{12} & $\angle R P 1$ & rs11172113 & $\mathrm{FEV}_{1} / \mathrm{FVC}$ & $T /-0.032 / 1.24 \mathrm{e}-08$ & T/0.407/0.006/0.038 & $\mathrm{T} / 0.428 / 0.004 / 0.1701$ & $\mathrm{~T} / 0.415 /-0.004 / 0.01385$ \\
\hline & & 57527283 & & & & & \\
\hline \multirow[t]{2}{*}{12} & CCDC38 & rs1036429 & $\mathrm{FEV}_{1} / \mathrm{FVC}$ & $\mathrm{T} / 0.038 / 2.30 \mathrm{e}-11$ & C/0.21/0.006/0.050 & C/0.162/0.004/0.399 & $\mathrm{T} / 0.809 / 0.004 / 0.06425$ \\
\hline & & 96271428 & & & & & \\
\hline \multirow[t]{2}{*}{15} & THSD4 & rs12899618 & $\mathrm{FEV}_{1} / \mathrm{FVC}$ & G/0.076/1.86e-15 & G/0.152/-0.012/0.0007 & G/0.12/-0.009/0.0507 & $\mathrm{A} / 0.854 /-0.009 / 2.8 \mathrm{e}-04$ \\
\hline & & 71645120 & & & & & \\
\hline \multirow[t]{2}{*}{16} & MMP15 & rs12447804 & $\mathrm{FEV}_{1} / \mathrm{FVC}$ & T/-0.038/3.59e-08 & T/0.79/-0.002/0.598 & T/0.938/-0.001/0.911 & Т/0.191/0.002/0.528 \\
\hline & & 58075282 & & & & & \\
\hline \multirow[t]{2}{*}{16} & CFDP1 & rs2865531 & $\mathrm{FEV}_{1} / \mathrm{FVC}$ & T/0.031/1.77e-11 & $\mathrm{T} / 0.592 /-0.005 / 0.078$ & T/0.351/-0.006/0.05393 & A/0.522/-0.005/0.0742 \\
\hline & & 75390316 & & & & & \\
\hline \multirow[t]{2}{*}{21} & KCNE2 & rs9978142 & $\mathrm{FEV}_{1} / \mathrm{FVC}$ & $T /-0.043 / 2.65 \mathrm{e}-08$ & $\mathrm{~T} / 0.849 / 0.002 / 0.558$ & T/0.799/0.002/0.530 & A/0.83/0.001/0.677 \\
\hline & & 35652239 & & & & & \\
\hline
\end{tabular}

The SNP with the lowest $p$ value within each region or gene from the CHARGE/Spirometa consortium is listed ordered by chromosome number [10]. Quite a few SNPs met a nominal levels of significance using Bonferroni correction $(P<0.0018$ for the 28 regions tested)

*In Table 4, while this SNP is not significant in our cohort and meta-analysis, rs12048582 in the TGFB2 gene was genome wide significant ( $p$-value $=6.28 \mathrm{E}-09)$

\section{A comparison of post and pre bronchodilator $\mathrm{FEV}_{1}$ and $\mathrm{FEV}_{1}$ /FVC among NHW in the COPDGene cohort}

Post bronchodilator pulmonary function provides the ability to separate individuals with reversible pulmonary function impairments, which is indicative of asthma from those individuals whose pulmonary function is not reversible with a bronchodilator. Thus, measuring post bronchodilator spirometry provides a phenotype that is more homogeneous with respect to the nature of the pulmonary function impairment. We hypothesized that a GWA of post bronchodilator $\mathrm{FEV}_{1}$ and $\mathrm{FEV}_{1} / \mathrm{FVC}$ would be similar or more powerful than a GWA of pre bronchodilator $\mathrm{FEV}_{1}$ and $\mathrm{FEV}_{1} / \mathrm{FVC}$. To test this hypothesis, we performed a GWA of pre bronchodilator $\mathrm{FEV}_{1}$ and $\mathrm{FEV}_{1} / \mathrm{FVC}$ in the COPDGene cohort among NHW. The correlation between pre and post bronchodilator $\mathrm{FEV}_{1}$ is 0.95 and the correlation between pre and post bronchodilator $\mathrm{FEV}_{1} / \mathrm{FVC}$ is 0.98 . Additional file 1: Tables S13 and S14 show the genome wide significant results for these analyses. The results for the GWA of pre bronchodilator $\mathrm{FEV}_{1}$ are similar to those of post bronchodilator $\mathrm{FEV}_{1}$ among NHW in the COPDGene cohort. 12 SNPs on chromosome 15 [CHRNA3/5] are significantly associated with post bronchodilator $\mathrm{FEV}_{1}$ where as 8 SNPs in this region are significantly associated with pre bronchodilator $\mathrm{FEV}_{1}$. For both pre and post bronchodilator $\mathrm{FEV}_{1} / \mathrm{FVC}$, the same $8 \mathrm{SNPs}$ on chromosome 15 [CHRNA3/5] and the same 4 SNPS on chromosome 4 $[H H I P]$ are significantly associated with these measures. These comparisons suggest that previous GWAS [7-13] are not biased due to the inclusion of individuals with bronchodilator reversibility. There appears to be only a modest loss in signal in GWAS of pre bronchodilator $\mathrm{FEV}_{1}$ compared to post bronchodilator $\mathrm{FEV}_{1}$, and no apparent difference in the signal between pre and post bronchodilator $\mathrm{FEV}_{1} / \mathrm{FVC}$ ratio.

\section{Discussion}

To the best of our knowledge, this is the first GWAS of post bronchodilator pulmonary function. These analyses were performed in a large cohort of current and former smokers with the full range of pulmonary function from normal values to severely impaired. We identified multiple loci that were genome wide significant for post bronchodialater $\mathrm{FEV}_{1}$ and $\mathrm{FEV}_{1} / \mathrm{FVC}$ in both the COPDGene cohort and in the combined meta-analyses.

The most significant association for both $\mathrm{FEV}_{1}$ and $\mathrm{FEV}_{1} / \mathrm{FVC}$ among NHW in the COPDGene cohort and in the combined meta analysis was on chromosome 15q25 [CHRNA3]. This region contains a cluster of nicotinic receptors that are associated with nicotine dependence, COPD case status, lower limit of normal for pre bronchodilator airway obstruction, lung cancer, and other smoking related traits [14-23]. A recent analysis by our group suggested this region may both directly and indirectly affect COPD affection status through nicotine dependence [24]. Other genes within this region in linkage disequilibrium also demonstrate significant associations with post bronchodialator $\mathrm{FEV}_{1}$ and $\mathrm{FEV}_{1} / \mathrm{FVC}$ ratio including CHRNA5/B4, IREB2, AGPHD1, and ADAMTS7.

Our results suggest common genetic susceptibility to post bronchodilator $\mathrm{FEV}_{1}$ and $\mathrm{FEV}_{1} / \mathrm{FVC}$, pre bronchodilator measures of pulmonary function, and COPD affection status. We confirmed previous GWA association 
with HHIP, TGFB2, FAM13A, MMP12, MMP3, CYPA7, $C Y P 2 A 6$, and RIN3 from previous studies with our results on post bronchodilator FEV1 and FEV1/FVC.

\section{Significant Spirometry Results associated with COPD Affection status in COPDGene}

In this study, we found that multiple genetic determinants of COPD affection status were associated with spirometric measures of lung function in COPDGene. These results are not at all surprising, since COPD is defined by lung function thresholds. In the GWAS results of COPD and severe COPD affection status in COPDGene [25], there was a significant association with affection status and SNPs in the 15q25 region [CHRNA3, CHRNA5, CHRNB4, AGPHD1, and IREB2], HHIP on chromosome 4, FAM13A on chromosome 4, TGFB2 on chromosome 1, MMP3/ MMP12 on chromosome 11, and RIN3 on chromosome 14. We found evidence for all of these regions as genetic determinants of spirometric measures in COPDGene as well.

The region on $15 \mathrm{q} 25$ contains the genes CHRNA3, CHRNA5, CHRNB4, AGPHD1, and IREB2, and numerous GWA have shown evidence of association of this region with COPD, emphysema, lung cancer, and smoking intensity [14-23]. Regions near HHIP [26-28], FAM13A, and TGFB2 have been previously associated with lung function and COPD [8-10, 29]. In addition, SNPs in or near $A G E R$ have previously been reported in association with lung function and with emphysema [30].

The RIN3 locus on chromosome 14 has not been previously associated with lung function, although SNPs in RIN3 were associated with COPD affection status in the COPDGene study [25]. We identified an association near RIN3 with $\mathrm{FEV}_{1} / \mathrm{FVC}$ in the COPDGene cohort. RIN3, a Rab5 GTPase binding protein, is expressed in many tissues, including the lung [31, 32].

\section{Significant spirometry GWA results not significantly associated with affection status in COPDGene}

While not previously associated with lung function, $D B H$ on chromosome 9 has been associated with smoking intensity [33]. Our finding represents the first evidence of association of this locus with lung function. Although the SNP identified in this study (rs1108581) does not cause amino acid residue changes in DBH, gene expression may be modified either directly or through other variant(s) in strong LD. This view is supported by evidence that a genetic variant (C-1021T or rs1611115), located upstream of the DBH translational start site, accounts for $51 \%$ of the variation in plasma-DBH activity in NHW [33]. SNPs near CYP2A7 and CYP2A6 on chromosome 19 have been associated with lung cancer, cigarette smoking, and COPD $[34,35]$. Notably, both of these loci were significant despite adjustment for cigarette smoking status.

\section{Novel nature of COPDGene study}

The COPDGene study is novel in several ways. There are many subjects with severe and very severe COPD (GOLD spirometry grades 3-4). There were sufficient numbers of both AA and NHW subjects to allow reasonable power to detect a genetic association with quantitative spirometric measures in these stratified samples. COPDGene has carefully collected standardized spirometric measures and post-bronchodilator spirometry. In addition, all COPDGene subjects were former or current smokers.

\section{Potential limitations}

The COPDGene cohort was ascertained based on smoking status and GOLD stage. Analysing secondary phenotypes in a case-control study can be biased due to this ascertainment condition. However, this is only an issue for SNPs associated with both the ascertainment condition and the secondary phenotype. Since our analysis focused on measures of pulmonary function (one of the primary ascertainment conditions) and adjusted for smoking status, our analysis should be robust against this sampling bias [36]. While COPDGene includes both AA and NHW, the sample size of AA subjects was considerably smaller and therefore had limited statistical power.

\section{Conclusions}

The GWA of lung function measures in COPDGene identified a novel locus on chromosome 9/DBH among NHW as being associated with common spirometric measures, and replicated multiple previously reported genetic loci for lung function. Further research will be required to determine the functional genetic variants within these regions of association.

\section{Methods COPDGene study subjects}

COPDGene is a multi-center study performed in the United States that has been described in detail previously [37]. The COPDGene study included 10,192 current and former smoking participants with at least 10 packyears of cigarette smoking history and ages ranging from 45-81. Table 1 details characteristics of the COPDGene participants included in the genome-wide association analysis. We excluded subjects from the analysis with severe alpha-1 antitrypsin deficiency, genotyping failure, or spirometric tests which failed quality control review. This resulted in 9919 subjects (6659 NHW and 3260 AA). Among these subjects, there were 3641 COPD cases (2812 NHW and 821 AA) defined as having Global Initiative for Chronic Obstructive Lung Disease (GOLD) spirometry stages 2-4. 
with post-bronchodilator FEV1/FVC $<0.70$ and FEV1 $<$ $80 \%$ of predicted values.

\section{Post bronchodilator spirometry measurements}

Spirometry in COPDGene was performed using a standardized spirometer (EasyOne by ndd Medical Technologies, Inc, Andover, MA). Spirometry was performed at baseline and repeated approximately $20 \mathrm{~min}$ after two puffs (180 mcg) of albuterol administered through a spacer. The analyses in this manuscript focused on the postbronchodilator spirometric values. Pulmonary function measurements were collected according to the American Thoracic Society/European Respiratory Society guidelines [38]. Methodology for spirometric measures have been described in detail previously [37].

\section{Genotyping, quality control and imputation}

All COPDGene subjects were genotyped using the Illumina HumanOmniExpress by Illumina (San Diego, CA). Details of genotyping quality control have been previously described [25]. Imputation on the COPDGene cohorts was performed using $\mathrm{MaCH}$ and minimac $[39,40]$. Prephasing and imputation were both performed using 30 rounds and 200 states, with regions divided into 1 megabase and $500 \mathrm{~kb}$ flanks. Reference panels for the NHW and AA subjects were the 1000 Genomes Phase I v3 European (EUR) and cosmopolitan reference panels, respectively [41]. Variants with an $\mathrm{R}$-squared value of $\leq 0.3$ were removed from further analysis. SNPs with minor allele frequency less than $1 \%$ were excluded. Further details concerning genotyping, quality control, and imputation are posted on the COPDGene website (http:// www.copdgene.org). All SNP genomic locations are based on the NCBI37/hg19 assembly.

\section{Meta-analysis study populations: ECLIPSE and GenKOLS}

The Evaluation of COPD Longitudinally to Identify Predictive Surrogate Endpoints (ECLIPSE) was a longitudinal, prospective, observational study conducted at 46 clinical centers in 12 countries with genome-wide SNP data available from 1764 COPD cases and 178 current or ex-smoking controls [42]. The GenKOLS GWAS cohort consists of 863 COPD cases and 808 controls from Bergen, Norway. Genotyping methods and study descriptions for the GenKOLS and ECLIPSE cohorts have been described previously [43, 44]. We limited our analysis in both studies to current or ex-smokers of European descent.

\section{Statistical analyses}

GWA analyses were performed in PLINK (v1.07) and were stratified by race [45]. Linear regression analyses of
$\mathrm{FEV}_{1}$ and the ratio of $\mathrm{FEV}_{1} / \mathrm{FVC}$ were adjusted for age, gender, pack-years, height and genetic ancestry (as summarized by principal components) by including these covariates in the model. The primary analyses were performed on the whole cohort (including smoking controls with normal spirometry and GOLD stages 2 to 4 COPD in all cohorts, and additionally individuals with unclassified spirometry $\left[\mathrm{FEV}_{1}<80 \%\right.$ predicted but $\mathrm{FEV}_{1} / \mathrm{FVC} \geq 0.7$ ], and GOLD stage $1 \mathrm{COPD}$ with $\mathrm{FEV}_{1} \geq$ $80 \%$ predicted but $\mathrm{FEV}_{1} / \mathrm{FVC}<0.7$ in COPDGene). A secondary analysis was limited to only GOLD 2-4 cases.

A fixed effects meta-analysis was performed using METAL (v 2010-08-01) [46] for $\mathrm{FEV}_{1}$ and $\mathrm{FEV}_{1} / \mathrm{FVC}$, adjusting for the same covariates mentioned above (age, gender, pack-years, height, genetic ancestry as summarized by principal components) for the COPDGene, ECLIPSE, and GenKOLS cohorts. Genome-wide significant associations were defined by $P<5 \times 10^{-8}$. Suggestive associations were defined as $5 \times 10^{-7}<P<$ $5 \times 10^{-8}$.

\section{Ethics}

The COPDGene, ECLIPSE, and GenKOLS studies were all approved by the respective clinical center institutional review boards. The COPDGene, ECLIPSE, and GenKOLS studies met IRB protocol approved by the NHLBI for human subjects research. For the COPDGene study and the meta-analysis study conducted in this manuscript, we have obtained IRB approval from the Colorado Multiple Institutional Review Board (COMIRB) at the University of Colorado, Colorado School of Public Health.

\section{Consent}

We have obtained written informed consent from the subjects to participate in these studies. We have obtained written informed consent to publish from the participants of the COPDGene, ECLIPSE and GenKOLS studies and no individual patient data or individual clinical data is presented in this manuscript.

\section{Availability of data and materials}

The datasets used in this paper can be found at http:// www.ncbi.nlm.nih.gov/projects/gap/cgi-bin/study.cgi? study_id=phs000179.v1.p1

\section{Additional file}

Additional file 1: The supplement for this manuscript contains the following information, tables, and figures. The COPD

Foundation funding and a list of the COPDGene and ECLIPSE investigators are given in the supplement. Tables S1-S12 list the top SNPS with a $p$-value $<5 \mathrm{E}-06$ for $\mathrm{FEV}_{1}$ and $\mathrm{FEV}_{1} / \mathrm{FVC}$ for all subjects and cases only among AA in the COPDGene study, NHW in the COPDGene study, and in the meta-analysis of the COPDGene, ECLIPSE 
and the GenKOLS studies. Tables S13 and S14 provide a comparison of genome-wide significant results for pre and post bronchodilator $\mathrm{FEV}_{1}$ and $\mathrm{FEV}_{1} / \mathrm{FVC}$ among NHW in the COPDGene study. Figures $\mathrm{S} 1$ and $\mathrm{S} 2$ are region plots for the genome-wide significant results for $\mathrm{FEV}_{1}$ and $\mathrm{FEV}_{1} / \mathrm{FVC}$, respectively, in the meta-analysis. (DOC $15181 \mathrm{~kb}$ )

\section{Abbreviations}

COPD: Chronic obstructive pulmonary disease; SNP: Single nucleotide polymorphism; MAF: Minor allele frequency; AA: African American; NHW: Non-Hispanic White; $\mathrm{FEV}_{1}$ : Forced expiratory volume in the first second; FVC: Forced vital capacity, the total volume of air expired after a maximal inhalation; GWAS: Genome wide association study.

\section{Competing interests}

Regarding conflicts of interest, in the past three years, Edwin K. Silverman received honoraria and consulting fees from Merck and grant support and consulting fees from GlaxoSmithKline. Craig Hersh received lecture fee from Novartis and consulting fees from CSL Behring. David Lomas is a consultant and has received grant support and honoraria from GlaxoSmithKline. He chairs the Respiratory Therapy Area Board at GlaxoSmithKline. No other authors reported conflicts of interest. The funding sources played no role in the design of the study or the decision to submit the manuscript for publication.

\section{Authors' contributions}

$S L$ and $M C$ ran the statistical analyses. SL and KY produced the figures and tables for the manuscript and supplement. ES and $J \mathrm{H}$ supervised the project. $S L, M C, K Y, C H, P C, M M, E R, M M, D D, M P, M F, B M, R J, R C, D L, S B, P B, A G, J C$, $T B, N L, C L, J H$, and ES were involved in drafting and editing the paper, directing the analyses, and assisting in the literature review. All authors read and approved the final manuscript.

\section{Acknowledgements}

Research reported in this publication was supported by the National Heart, Lung, And Blood Institute of the National Institutes of Health under Award Number K01HL125858 (S.M.L.). The content is solely the responsibility of the authors and does not necessarily represent the official views of the National Institutes of Health.

This work was also supported by National Heart, Lung and Blood Institute NHLBI R01 HL084323, P01 HL083069, P01 HL105339 and R01 HL089856 (E.K.S.); K08 HL097029 and R01 HL113264 (M.H.C.), and R01 HL089897 (J.D.C.) and a grant from the Alpha-1 Foundation (M.H.C.). The COPDGene study (NCT00608764) is also supported by the COPD Foundation through contributions made to an Industry Advisory Board comprised of AstraZeneca, Boehringer Ingelheim, Novartis, Pfizer, GlaxoSmithKline, Siemens, and Sunovion. The Norway GenKOLS study (Genetics of Chronic Obstructive Lung Disease, GSK code RES1 1080), and the ECLIPSE study (NCT00292552; GSK code SCO104960) were funded by GlaxoSmithKline.

The funding sources played no role in the design of the study or the decision to submit the manuscript for publication.

\section{Author details}

${ }^{1}$ Department of Biostatistics, University of Colorado Anschutz Medical Campus, 13001 E. 17th Place, B119 Bldg. 500, W3128, Aurora, CO 80045, USA. ${ }^{2}$ Channing Division of Network Medicine, Brigham and Women's Hospital, Harvard Medical School, Boston, MA, USA. ${ }^{3}$ Department of Epidemiology, Colorado School of Public Health, University of Colorado Anschutz Medical Campus, Aurora, CO, USA. ${ }^{4}$ Department of Medicine, National Jewish Health, Denver, CO, USA. ${ }^{5}$ Department of Epidemiology, Johns Hopkins Bloomberg School of Public Health, Baltimore, MD, USA. ${ }^{6}$ Morehouse School of Medicine, Atlanta, GA, USA. ${ }^{7}$ Division of Pulmonary, Allergy \& Critical Care Medicine, LDS Hospital, Salt Lake City, UT, USA. ${ }^{\circledR}$ Los Angeles Biomedical Research Institute at Harbor-UCLA Medical Center, Torrance, CA, USA. ${ }^{9}$ Wolfson Institute for Biomedical Research, University College London, London, UK. ${ }^{10}$ Division of Pulmonary, Allergy, and Critical Care Medicine, University of Alabama at Birmingham, Birmingham, AL, USA. ${ }^{11}$ Department of Clinical Science, University of Bergen, Bergen, Norway. ${ }^{12}$ Department of Biostatistics, Harvard School of Public Health, Boston, MA, USA.
Received: 27 February 2015 Accepted: 20 November 2015

\section{Published online: 03 December 2015}

\section{References}

1. Minino A, Xu J, Kochanek K. Deaths: preliminary data for 2008. Natl Vital Stat Rep. 2010;59:1-52.

2. Wan ES, Silverman EK. Genetics of COPD and emphysema. Chest. 2009;136:859-66.

3. Weiss ST. Lung function and airway diseases. Nat Genet. 2010;42(1):14-6.

4. Silverman EK, Vestbo J, Agusti A, Anderson W, Bakke PS, Barnes KC, et al. Opportunities and challenges in the genetics of COPD 2010: an International COPD Genetics Conference report. COPD. 2011;8:121-35.

5. Rabe KF, Hurd S, Anzueto A, Barnes PJ, Buist SA, Calverley P, et al. Global Initiative for Chronic Obstructive Lung Disease. Global strategy for the diagnosis, management, and prevention of chronic obstructive pulmonary disease: Gold executive summary. Am J Respir Crit Care Med. 2007;176:532-55.

6. Wilk JB, DeStefano AL, Arnett DK, Rich SS, Djousse L, Crapo RO, et al. A genome-wide scan of pulmonary function measures in the National Heart, Lung, and Blood Institute Family Heart Study. Am J Respir Crit Care Med. 2003;167:1528-33.

7. Wilk JB, Chen TH, Gottlieb DJ, Walter RE, Nagle MW, Brandler BJ, et al. A genome-wide association study of pulmonary function measures in the Framingham Heart Study. PLoS Genet. 2009;3(5):e1000429.

8. Hancock DB, Eijgelsheim M, Wilk JB, Gharib SA, Loehr LR, Marciante KD, et al. Meta-analyses of genome-wide association studies identify multiple loci associated with pulmonary function. Nat Genet. 2010;42:45-52.

9. Repapi E, Sayers I, Wain LV, Burton PR, Johnson T, Obeidat M, et al. Genome-wide association study identifies five loci associated with lung function. Nat Genet. 2010;42:36-44

10. Soler Artigas M, Loth DW, Wain LV, Gharib SA, Obeidat M, Tang W, et al. Genome-wide association and large-scale follow up identifies 16 new loci influencing lung function. Nat Genet. 2011;43:1082-90.

11. Wilk JB, Shrine NRG, Loehr LR, Zhao JH, Manichaikul A, Lopez LM, et al. Genome-Wide Association Studies Identify CHRNA5/3 and HTR4 in the Development of Airflow Obstruction. Am J Respir Crit Care Med. 2012; 186(7):622-32.

12. Siedlinski M, Cho MH, Bakke P, Gulsvik A, Lomas DA, Anderson W, et al. Genome-wide association study of smoking behaviours in patients with COPD. Thorax. 2011;66(10):894-902.

13. Thyagarajan B, Wojczynski M, Minster RL, Sanders J, Barral S, Christiansen L, et al. Genetic variants associated with lung function: the long life study. Respir Res. 2014;15:134.

14. Lambrechts D, Buysschaert I, Zanen P, Coolen J, Lays N, Cuppens H, et al. The 15q24/25 susceptibility variant for lung cancer and chronic obstructive pulmonary disease is associated with emphysema. Am J Respir Crit Care Med. 2010;181:486-93.

15. Castaldi PJ, Cho MH, Litonjua AA, Bakke P, Gulsvik A, Lomas DA, et al. The association of genome-wide significant spirometric loci with COPD susceptibility. Am J Respir Cell Mol Biol. 2011;45:1147-53.

16. DeMeo DL, Mariani T, Bhattacharya S, Srisuma S, Lange C, Litonjua A, et al. Integration of genomic and genetic approached implicates IREB2 as a COPD susceptibility gene. Am J Hum Genet. 2009;85:493-502.

17. Zhang J, Summah H, Zhu YG, Qu JM. Nicotinic acetylcholine receptor variants associated with susceptibility to chronic obstructive pulmonary disease: a meta-analysis. Respir Res. 2011;12:158.

18. Hardin M, Zielinski J, Wan ES, Hersh CP, Castaldi PJ, Schwinder E, et al. CHRNA3/5, IREB2, and ADCY2 Are Associated with Severe Chronic Obstructive Pulmonary Disease in Poland. Am J Respir Cell Mol Biol. 2012; 47(2):203-8

19. Hung RJ, McKay JD, Gaborieau V, Boffetta P, Hashibe M, Zaridze D, et al. A susceptibility locus for lung cancer maps to nicotinic acetylcholine receptor subunit genes on 15q25. Nature. 2008;452:633-7.

20. Amos Cl, Wu X, Broderick P, Gorlov IP, Gu J, Eisen T, et al. Genome-wide association scan of tag SNPs identifies a susceptibility locus for lung cancer at 15q25.1. Nat Genet. 2008;40:616-22.

21. Gu M, Dong X, Zhang X, Wang X, Qi Y, Yu J, et al. Strong Association between Two Polymorphisms 15q25.1 on and Lung Cancer Risk: A MetaAnalysis. Plos ONE. 2012;7(6):e37970

22. Spitz MR, Amos Cl, Dong Q, Lin J, Wu X. The CHRNA5-A3 Region on Chr 15q24-25.1 is a Risk Factor Both for Nicotine Dependence and for Lung Cancer. J Natl Cancer Inst. 2008;100:1552-6. 
23. Sakoda LC, Loomis MM, Doherty JA, Neuhouser ML, Barnett MJ, Thornquist MD, et al. Chr 15q24-25.1 variants, diet, and lung cancer susceptibility in cigarette smokers. Cancer Causes Control. 2011;22:449-61.

24. Siedlinski M, Tingley D, Lipman PJ, Cho MH, Litonjua AA, Sparrow D, et al. Dissecting direct and indirect genetic effects on chronic obstructive pulmonary disease (COPD) susceptibility. Hum Genet. 2013;132(4):431-41.

25. Cho MH, McDonald MN, Zhou X, Siedlinski M, Hersh CP, Demeo DL, et al. A genome-wide association identifies risk loci for severe chronic obstructive pulmonary disease. Lancet Respir. 2014;2:214-25.

26. Zhou X, Baron RM, Hardin M, Cho MH, Zielinski J, Hawrylkiewicz I, et al. Identification of a chronic obstructive pulmonary disease genetic determinant that regulates HHIP. Hum Mol Genet. 2012;21:1325-35.

27. Young RP, Whittington CF, Hopkins RJ, Hay BA, Epton MJ, Black PN, et al. Chr 4q31 locus in COPD is also associated with lung cancer. Eur Respir J. 2010:36:1375-82.

28. Van Durme YM, Eijgelsheim M, Joos GF, Hofman A, Uitterlinden AG, Brusselle GG, et al. Hedgehog-interacting protein is a COPD susceptibility gene: the Rotterdam Study. Eur Respir J. 2010;36:89-95

29. Young RP, Hopkins RJ, Hay BA, Whittington CF, Epton MJ, Gamble GD. FAM13A locus in COPD is independently associated with lung cancerevidence of a molecular genetic link between COPD and lung cancer. Appl Clin Genet. 2011:4:1-10.

30. Manichaikul A, Hoffman EA, Smolonska J, Gao W, Cho MH, Baumhauer H, et al. Genome-wide study of percent emphysema on computed tomography in the general population. The multi-ethnic study of atherosclerosis lung/SNP Health Association Resource Study. Am J Respir Crit Care Med. 2014;189(4):408-18.

31. Kajiho H, Saito K, Tsujita K, Kontani K, Araki Y, Kurosu H, et al. RIN3: a novel Rab5 GEF interacting with amphiphysin II involved in the early endocytic pathway. J Cell Sci. 2003;116:4159-68.

32. Saito K, Murai J, Kajiho H, Kontani K, Kurosu H, Katada T. A novel binding protein composed of homophilic tetramer exhibits unique properties for the small GTPase Rab5. J Biol Chem. 2002;277:3412-8.

33. Zabetian CP, Anderson GM, Buxbaum SG, Elston RC, Ichinose H, Nagatsu T, et al. A quantitative-trait analysis of human plasma-dopamine betahydroxylase activity: evidence for a major functional polymorphism at the DBH locus. Am J Hum Genet. 2001;68:515-22.

34. Wang L, Zang W, Liu J, Xie D, Ji W, Pan Y, et al. Association of CYP2A6*4 with susceptibility of lung cancer: a meta-analysis. PLoS One. 2013;8(4): e59556.

35. Cho MH, Castaldi PJ, Wan ES, Siedlinski M, Hersh CP, Demeo DL, et al. A genome-wide association study of COPD identifies a susceptibility locus on chr 19q13. Hum Mol Genet. 2012;21:947-57.

36. Lutz SM, Hokanson JE, Lange C. An alternative hypothesis testing strategy for secondary phenotype data in case-control genetic association studies. Front Genet. 2014; (In Press) (doi:10.3389/fgene.2014.00188)

37. Regan EA, Hokanson JE, Murphy JR, Make B, Lynch DA, Beaty TH, et al. Genetic epidemiology of COPD (COPDGene) study design. COPD. 2010;7: 32-43.

38. Miller MR, Hankinson J, Brusasco V, Burgos F, Casaburi R, Coates A, et al. Standardisation of spirometry. Eur Respir J. 2005;26:319-38.

39. Howie B, Fuchsberger C, Stephens M, Marchini J, Abecasis GR. Fast and accurate genotype imputation in genome-wide association studies through pre-phasing. Nat Genet. 2012;44:955-9.

40. Li Y, Willer CJ, Ding J, Scheet $P$, Abecasis GR. MaCH: sing sequence and genotype data to estimate haplotypes and unobserved genotypes. Genet Epidemiol. 2010;834:816-34

41. 1000 Genomes Project Consortium, Abecasis GR, Auton A, Brooks LD, DePristo MA, Durbin RM, et al. An integrated map of genetic variation from 1,092 human genomes. Nature. 2010;491:56-65.

42. Vestbo J, Anderson W, Coxson HO, Crim C, Dawber F, Edwards L, et al. Evaluation of COPD Longitudinally to Identify Predictive Surrogate Endpoints (ECLIPSE). Eur Respir J. 2008;31:869-73.

43. Pillai SG, Ge D, Zhu G, Kong X, Shianna KV, Need AC, et al. A genome-wide association study in chronic obstructive pulmonary disease (COPD): Identification of two major susceptibility loci. PLoS Genet. 2009;5(3): e1000421
44. Cho MH, Boutaoui N, Klanderman BJ, Sylvia JS, Ziniti JP, Hersh CP, et al Variants in FAM13A are associated with chronic obstructive pulmonary disease. Nat Genet. 2010;42(3):200-1.

45. Purcell S, Neale B, Todd-Brown K, Thomas L, Ferreira MA, Bender D, et al. PLINK: a tool set for whole-genome association and population-based linkage analyses. Am J Hum Genet. 2007;81:559-75.

46. Willer CJ, Li Y, Abecasis GR. METAL: fast and efficient meta-analysis of genomewide association scans. Bioinformatics. 2010;26:2190-1.

\section{Submit your next manuscript to BioMed Central and we will help you at every step:}

- We accept pre-submission inquiries

- Our selector tool helps you to find the most relevant journal

- We provide round the clock customer support

- Convenient online submission

- Thorough peer review

- Inclusion in PubMed and all major indexing services

- Maximum visibility for your research 